\title{
Translation and Validation of the Indonesian Version of the Hypertension Self-care Profile
}

\author{
Arif Setyo Upoyo* ${ }^{1 *}$, Agis Taufik ${ }^{1}$, Akhyarul Anam ${ }^{1}$, Nuriya Nuriya ${ }^{1}$, Saryono Saryono ${ }^{1}$, Ismail Setyopranoto ${ }^{2}$, \\ Heny Suseani Pangastuti ${ }^{3}$
}

${ }^{1}$ Department of Nursing, Health Sciences Faculty, Jenderal Soedirman University, Purwokerto, Indonesia; ${ }^{2}$ Department of Neurology, Medicine Public Health and Nursing Faculty, Gadjah Mada University, Yogyakarta, Indonesia; ${ }^{3}$ Department of Medical and Surgical Nursing, Medicine Public Health and Nursing Faculty, Gadjah Mada University, Yogyakarta, Indonesia

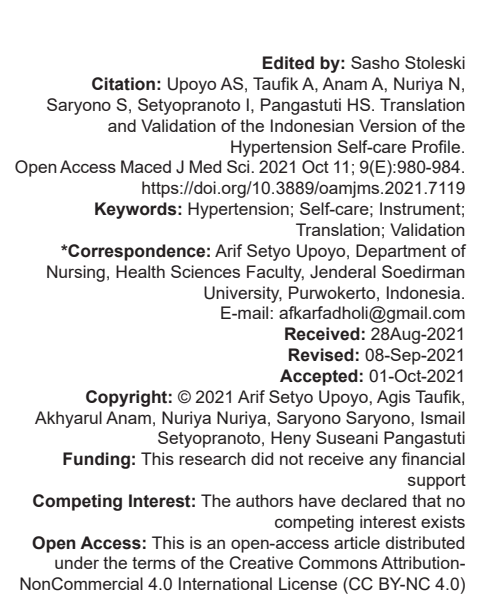

\begin{abstract}
BACKGROUND: High blood pressure self-care profile (HBP-SCP) is one of the instruments that needed to evaluate education program among hypertension patients.

AIM: The purpose of the study was to translate and validate HBP-SCP into Indonesian version.

METHODS: This study involved translation, content validation, and psychometric testing. The first instrument was conducted forward and backward translation by experts. Seven expert reviewed the contents for consistency, clarity, difficulty, representativeness, and suitability for inclusion. Finally, instrument was tested for reliability and validity on 40 hypertensive patients using Cronbach's alpha and Pearson's moment product.

RESULTS: The final Indonesian version of HBP-SCP included behavior, motivation, and self-efficacy that each consists of 20 items questions were valid and reliable with positive expert review ratings (content validity index 0.964 ) internal consistency reliability coefficient ranged from 0.911 to 0.955 . Items questionnaire of Indonesian version of HBP-SCP had strong correlation and significant validity $(p \leq 0.05)$

CONCLUSION: Indonesian version of HBP-SCP is a valid and reliable instrument to assess behavior, motivation, and self-efficacy among hypertension patients and evaluate group based hypertension education programs in Indonesia.
\end{abstract}

\section{Introduction}

Hypertension is a serious medical condition that significantly increases the risks of cardiovascular diseases. Reducing the prevalence of hypertension by $25 \%$ by 2025 is one of the global targets for noncommunicable diseases [1]. In Indonesia, the prevalence of hypertension continues to increase. Based on Basic Health Research in 2013, the prevalence of hypertension was $25.8 \%$, while in 2018 increased to $34.1 \%$ [2]. Based on Indonesia Family Life Survey-5, the prevalence of hypertension among study participants in Indonesia was $33.4 \%$, males $31.0 \%$, and among females $35.4 \%$ [3].

Hypertension can be diagnosed when patients systolic blood pressure (SBP) is $\geq 140 \mathrm{mmHg}$ and/or their diastolic blood pressure (DBP) is $\geq 90 \mathrm{mmHg}$ following repeated examination [4]. Risk factors of hypertension include age, smoking history, excessive salt consumption, physical activity, lack of alcohol consumption, obesity, nonadherence to therapy, and secondary diseases including diabetes, hypercholesterolemia, myocardial infarction, and kidney disease. Prevalence of hypertension was higher among persons with comorbidities (diabetes $64.5 \%$, transient ischemic attack $54.7 \%$, and heart disease $64.4 \%$ ) and prevalence was lower among persons who did regular vigorous intensity exercise versus those who did moderate intensity exercise $(32 \%$ vs. $45.7 \%$ ) and among nonsmokers versus smokers (42.2\% vs. $46.6 \%)$ [5].

Uncontrolledblood pressure(BP)inhypertensive patients can increase the risk of cardiovascular disease. Factors that influence uncontrolled BP based on a systematic review and meta-analysis include medication non-adherence, hypertension stage, atrial fibrillation, triglycerides, and use of antihypertensive drugs [6]. Based on large cohort studies, high BP is an important risk factor for heart failure, atrial fibrillation, chronic kidney disease, heart valve diseases, aortic syndromes, and dementia, in addition to coronary heart disease and stroke [7]. Factors related to stroke prevention behavior among hypertensive patients include self-efficacy, perception, and awareness of stroke risk [8].

Knowledge of risk factors and lifestyle is important for controlling BP in hypertensive patients. 
However, $64.8 \%$ of hypertension patients' knowledge was low [9]. Another factor that affects the healthy lifestyle of hypertensive patient is low self-awareness. The results of research state that the rates of awareness, treatment, and control of hypertension were $44.9 \%$, $36.5 \%$, and $24.3 \%$ [10].

Health education program is needed to increase knowledge, awareness, and lifestyle of hypertensive patients. Education is effective to controlling BP [11]. Health education in hypertensive patients can be done individually or in groups to control risk factors that can be changed through lifestyle changes. Lifestyle intervention recommended for hypertensive patient includes stop smoking, healthy diet and drinks, regular exercise, lose weight, salt reduction, and lower alcohol intake [4]. In order for the program can be evaluated, an instrument to measure the success of the program is needed. One of the self-care instruments for hypertensive patients is the high BP self-care profile (HBP-SCP) developed by Han et al. The instrument can measure the self-care behavior, motivation, and self-efficacy of hypertensive patients [12]. The purpose of the study is to translate and validate HBP-SCP into Indonesian version.

\section{Methods}

This research was conducted by cross sectional. The population in this study were seven experts and 40 hypertensive patients in the community of the Central Java region of Indonesia. The research was conducted in June 2020-February 2021 after obtaining ethical clearance from the Ethics Commission of Medicine, Public Health and Nursing Faculty of Gadjah Mada University Ref. No.: KE/FK/0621/EC2020. This study involved translation, validation, and reliability testing (Figure 1).

\section{Translation procedure}

The first instrument was conducted forward and backward translation by two professional translator Jenderal Soedirman University. The translator consists of English language expert and expert in health science. After translated language into Bahasa Indonesia, the two experts compared the original HBP-SCP version with the results of the back translated Indonesian version instrument. Next, we conducted discussions and adjustments in Indonesian to get the final version which ready for use in the study.

\section{Content validity procedure}

Content validity is performed by experts with different backgrounds, usually seven or more

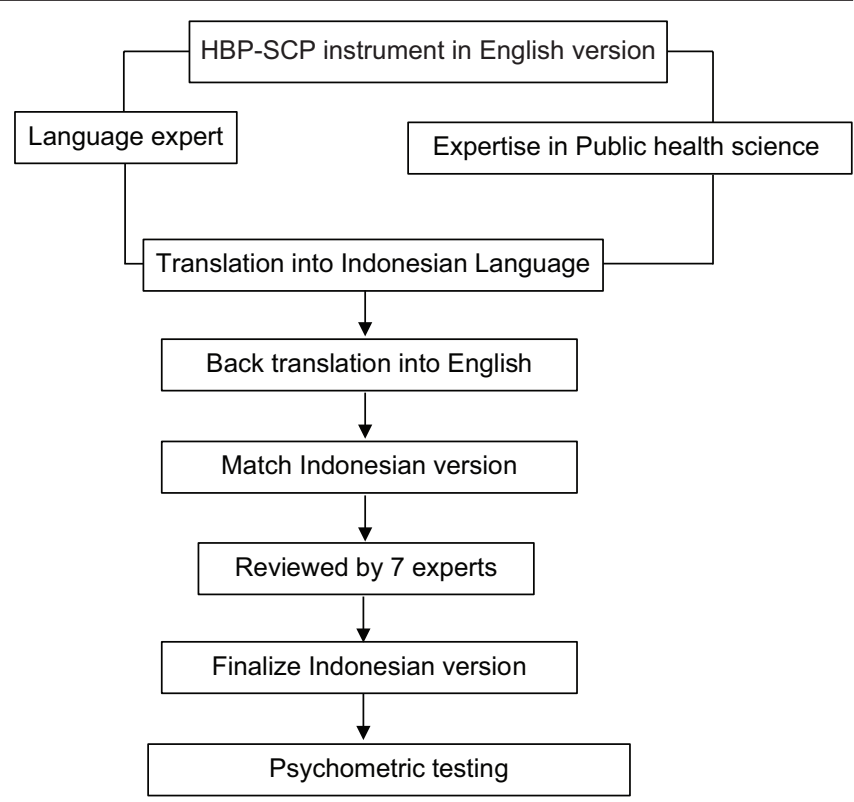

Figure 1: Processes of translational and validation of the Indonesian version of high blood pressure self-care profile

experts [13]. The expert consists of seven people including specialist doctor, nursing lecturer, health center nurse, nutritionists, public health expert, pharmacist, and sociologist. Experts received explanatory sheets about the objectives, validation procedures, and translated instruments before review. Experts reviewed HBP-SCP which consisted of behaviors, motivation, and self-efficacy, each consisting of 20 question items. Experts reviewed the contents for consistency, clarity, difficulty, representativeness, and suitability for inclusion by providing a dichotomous response scale: "Clear $=1$ " versus "not clear $=0$." The experts also provided suggestions to improve clarity the questionnaire items.

\section{Psychometric testing}

Instruments that have been validated by the experts are corrected according to the suggestions of the experts and then pilot testing is carried out to test the validity and reliability. Forty hypertensive patients who are active in Integrated Health Care Center (Posyandu) in Central Java participated as respondents. The questionnaire which is distributed to the respondents contains the explanation of the questionnaire and the instructions for each of HBPSCP component questions. Instructions for behavioral questions are "How often do you do the following?" For motivational questions is "How important is it for you to do the following?" and for self-efficacy questions is "How confident are you that you could do the following?" The instructions have been translated into Indonesian. Respondents gave responses on a 1-4 Likert scale. Never, sometimes, often, and always are the answer to a behavioral item questions. Not important, less important, important, and very 
Table 1: CVI of Indonesian version of HBP-SCP: Behavior, motivation, and self-efficacy scale

\begin{tabular}{|c|c|c|c|c|c|c|}
\hline Experts & Consistency & Clarity & Inclusion & Difficulty & Representativeness & Total score \\
\hline Neurologist & $20 / 20$ & $20 / 20$ & $20 / 20$ & $20 / 20$ & $20 / 20$ & $100 / 100$ \\
\hline Nursing lecturer & $20 / 20$ & $18 / 20$ & $20 / 20$ & $17 / 20$ & $20 / 20$ & $95 / 100$ \\
\hline Nurse (public health center) & $20 / 20$ & $18 / 20$ & $20 / 20$ & $18 / 20$ & $20 / 20$ & $96 / 100$ \\
\hline Nutritionist & $20 / 20$ & $20 / 20$ & $20 / 20$ & $20 / 20$ & $20 / 20$ & $100 / 100$ \\
\hline Public health expert & $20 / 20$ & $20 / 20$ & $20 / 20$ & $20 / 20$ & $20 / 20$ & $100 / 100$ \\
\hline Pharmacist & $20 / 20$ & $20 / 20$ & $20 / 20$ & $17 / 20$ & $20 / 20$ & $97 / 100$ \\
\hline Sociologist & $20 / 20$ & $14 / 20$ & $20 / 20$ & $18 / 20$ & $20 / 20$ & $92 / 100$ \\
\hline Score & & & & & & $675 / 700$ \\
\hline CVI & & & & & & 0.964 \\
\hline
\end{tabular}

important are the answers to motivational questions and unsure, not sure, and very sure are the answers to questions of self-efficacy. Furthermore, the data were analyzed using descriptive statistics for the sample characteristic, Cronbach's alpha coefficient for reliability, and data correlation using Pearson's moment product.

\section{Results}

The Indonesian version of HBP-SCP consists of 20 questions for behavior, 20 questions for motivation, and 20 questions for self-efficacy. The results of the content validity based on reviews from experts showed that content validity index $(\mathrm{CVI})=0.964$ (Table 1$)$. The experts gave recommendations that several question items needed to be modified because they were unclear or could be confusing. The modified question items included numbers 2, 3, 4, 10, 12, 16, and 17. The sociodemographic characteristics of hypertensive patients who participated in the validity and reliability test are presented in Table 2. Based on this table, it is known that the average participant is 61 years old, mostly female, basic education, low income, and has health insurance.

The results of the questionnaire validity and reliability are presented in Table 3 . The results of the reliability test showed that Cronbach's alpha value was more than 0.7 for all question components on the HBP-SCP questionnaire: Behavior (0.955), motivation (0.918), and self-efficacy (0.911). Pearson's correlation coefficients mostly show a strong correlation for self-care behavior, motivation, and self-efficacy questionnaires (Table 4). All HBP-SCP behavior question items had a strong correlation with $r=0.572-0.922(p<0.001)$. Most of the HBP-SCP motivation and self-efficacy question items also have a moderate to strong correlation with $r=0.368-0.846$ ( $p<0.001-0.010)$, except for question item number 15 which has a weak correlation $r=0.108(p=0.254)$ for motivation and $r=0.219(p=0.087)$ for self-efficacy.

\section{Discussion}

One of the nursing conceptual models to improve the independent behavior of patients in health care is the theory of self-care from Orem [14]. Orem developed the theory of nursing systems, selfcare deficits, and self-care. Self-care is a system of actions shown by a person in maintaining life, health, development, and welfare [15].

Table 2: Sociodemographic characteristic of hypertension patients $(n=40)$

\begin{tabular}{|c|c|c|}
\hline Characteristic & Frequency $(\%)$ & Mean (SD) \\
\hline Age (years) & & $61.67(10.72)$ \\
\hline \multicolumn{3}{|l|}{ Gender } \\
\hline Male & $12(30)$ & \\
\hline Female & $28(70)$ & \\
\hline \multicolumn{3}{|l|}{ Marital status } \\
\hline Single & $1(2.5)$ & \\
\hline Married & $27(67.5)$ & \\
\hline Widow/widower & $12(30)$ & \\
\hline \multicolumn{3}{|l|}{ Educational status } \\
\hline Primary & $33(82.5)$ & \\
\hline Senior high school & $6(15)$ & \\
\hline College/university & $1(2.5)$ & \\
\hline \multicolumn{3}{|l|}{ Working status } \\
\hline Not working & $16(40)$ & \\
\hline Laborer & $3(7.5)$ & \\
\hline Farmer & $17(42.5)$ & \\
\hline Government sector & $2(5)$ & \\
\hline Entrepreneur & $2(5)$ & \\
\hline \multicolumn{3}{|l|}{ Monthly income } \\
\hline $\begin{array}{l}<\text { Minimum regional } \\
\text { payment }\end{array}$ & $32(80)$ & \\
\hline $\begin{array}{l}\text { >Minimum regional } \\
\text { payment }\end{array}$ & $8(20)$ & \\
\hline \multicolumn{3}{|l|}{ Health assurance } \\
\hline No have & $4(10)$ & \\
\hline Have & $36(90)$ & \\
\hline \multicolumn{3}{|c|}{ Family history of hypertension } \\
\hline Yes & $8(20)$ & \\
\hline No & $32(80)$ & \\
\hline \multicolumn{3}{|l|}{ Blood pressure } \\
\hline Systole & $161.58(23.89)$ & \\
\hline Diastole & $94.27(10.56)$ & \\
\hline BMI & & $23.22(3.36)$ \\
\hline
\end{tabular}

The HBP-SCP instrument prepared by Han et al. is based on a valid theoretical framework from Orem, a published evidence based on hypertension care guidelines and a comprehensive area relevant to self-care for hypertensive patients [12]. Based on this concept, they developed the HBP-SCP instrument to measure self-efficacy, namely, HBP-SCP self-efficacy and hypertension patient self-care behavior (HBPSCP: Behavior). The results of the content validity of the Indonesian version of the HBP-SCP questionnaire by experts showed a $\mathrm{CVI}>0.9$ which indicated that the question items on the instrument were very relevant and clear. Experts recommend that the cutoff value for $\mathrm{CVI}$ is 0.75 [16]. Some of the questions were modified according to suggestions from experts which were 
adapted to the language, culture, and habits of the Indonesian people. For item question number 10, it needs to be modified with ingredients that contain high fat, for example, fried foods, coconut milk, and fatty foods. Food ingredients that contain high fat are listed in the Minister of Health Regulation no. 41 of 2014 concerning balanced nutrition [17]. For item question number 12, it is necessary to add the sentence "do not consume alcohol" because most Indonesians people do not consume alcohol because of culture and their belief.

Table 3: Reliabilities of Indonesian version of HBP-SCP scales

\begin{tabular}{llll}
\hline Scale & No. of items (response format) & Scale mean (SD) & Cronbach's alpha \\
\hline Behavior & $20(4$ points 1-4) & $69(13.85)$ & 0.955 \\
Motivation & $20(4$ points 1-4) & $74.25(7.65)$ & 0.918 \\
Self-efficacy & $20(4$ points 1-4) & $73.30(7.88)$ & 0.911 \\
\hline HBP-SCP: High blood pressure self-care profile. & &
\end{tabular}

Cronbach's alpha coefficient is applied to determine the consistency of the internal reliability instrument with the variable score using the Likert scale. Cronbach's alpha value of 0.7 or higher indicates good homogeneous among the items of the questionnaire [18]. The results of the Person' correlation coefficient for HBP-SCP showed a strong correlation and a significant $p$-value so that the instrument was declared valid. Based on data, HBP-SCP is a valid and reliable instrument to measure self-care behavior, motivation, and self-efficacy of hypertensive patients. Reliability can change when performed in different populations [19]. Therefore, HBP-SCP needs to be retested with a different or a wider population.

Table 4: Validity of Indonesian version of HBP-SCP scales

\begin{tabular}{|c|c|c|c|c|c|c|}
\hline \multirow[t]{2}{*}{ No. of items } & \multicolumn{2}{|c|}{ Behavior } & \multicolumn{2}{|c|}{ Motivation } & \multicolumn{2}{|c|}{ Self-efficacy } \\
\hline & $r$ & $\mathrm{p}$-value & $r$ & $\mathrm{p}$-value & $r$ & $\mathrm{p}$-value \\
\hline 1 & 0.748 & $<0.001$ & 0.600 & $<0.001$ & 0.675 & $<0.001$ \\
\hline 2 & 0.745 & $<0.001$ & 0.694 & $<0.001$ & 0.719 & $<0.001$ \\
\hline 3 & 0.572 & $<0.001$ & 0.846 & $<0.001$ & 0.774 & $<0.001$ \\
\hline 4 & 0.856 & $<0.001$ & 0.582 & $<0.001$ & 0.641 & $<0.001$ \\
\hline 5 & 0.801 & $<0.001$ & 0.701 & $<0.001$ & 0.721 & $<0.001$ \\
\hline 6 & 0.914 & $<0.001$ & 0.610 & $<0.001$ & 0.659 & $<0.001$ \\
\hline 7 & 0.684 & $<0.001$ & 0.705 & $<0.001$ & 0.760 & $<0.001$ \\
\hline 8 & 0.687 & $<0.001$ & 0.565 & $<0.001$ & 0.653 & $<0.001$ \\
\hline 9 & 0.922 & $<0.001$ & 0.823 & $<0.001$ & 0.758 & $<0.001$ \\
\hline 10 & 0.727 & $<0.001$ & 0.614 & $<0.001$ & 0.761 & $<0.001$ \\
\hline 11 & 0.857 & $<0.001$ & 0.673 & $<0.001$ & 0.682 & $<0.001$ \\
\hline 12 & 0.585 & $<0.001$ & 0.733 & $<0.001$ & 0.677 & $<0.001$ \\
\hline 13 & 0.693 & $<0.001$ & 0.645 & $<0.001$ & 0.681 & $<0.001$ \\
\hline 14 & 0.624 & $<0.001$ & 0.512 & $<0.001$ & 0.433 & 0.003 \\
\hline 15 & 0.709 & $<0.001$ & 0.108 & 0.254 & 0.219 & 0.087 \\
\hline 16 & 0.774 & $<0.001$ & 0.685 & $<0.001$ & 0.541 & $<0.001$ \\
\hline 17 & 0.690 & $<0.001$ & 0.656 & $<0.001$ & 0.651 & $<0.001$ \\
\hline 18 & 0.693 & $<0.001$ & 0.603 & $<0.001$ & 0.636 & $<0.001$ \\
\hline 19 & 0.867 & $<0.001$ & 0.477 & 0.001 & 0.480 & $<0.001$ \\
\hline 20 & 0.686 & $<0.001$ & 0.693 & $<0.001$ & 0.368 & 0.010 \\
\hline
\end{tabular}

\section{Conclusion}

The Indonesian version of HBP-SCP has good content coverage and positive expert review rating. It is a valid and reliable instrument to assess behavior, motivation, and self-efficacy among hypertension patients and relevant to evaluate group-based hypertension education programs in Indonesia. The authors recommend that the instrument needs to be tested for validity and reliability in the different or wider population.

\section{References}

1. World Health Organization. Hypertension. Geneva: World Health Organization; 2019. Available from: https:// www.who.int/news-room/fact-sheets/detail/hypertension. [Last accessed on 2021 Sep 13].

2. Ministry of Health of the Republic of Indonesia. The Reports of the Results of Basic Health Research; 2019. Available from: https://www.litbang.kemkes.go.id/laporan-riset-kesehatandasar-riskesdas. [Last accessed on $2020 \mathrm{Apr}$ 10].

3. Peltzer K, Pengpid S. The prevalence and social determinants of hypertension among adults in Indonesia: A crosssectional population-based national survey. Int J Hypertens. 2018;2018:5610725. https://doi.org/10.1155/2018/5610725 PMid:30174948

4. Unger T, Borghi C, Charchar F, Khan NA, Poulter NR, Prabhakaran D, et al. 2020 international society of hypertension global hypertension practice guidelines. Hypertension. Hypertension. 2020;75(6):1334-57. https://doi.org/10.1161/ hypertensionaha. 120.15026 PMid:32370572

5. Saju MD, Allagh KP, Scaria L, Joseph S, Thiyagarajan JA Prevalence, awareness, treatment, and control of hypertension and its associated risk factors: Results from baseline survey of SWADES family cohort study. Int J Hypertens. 2020;2020:4964835. https://doi.org/10.1155/2020/4964835 PMid:32351729

6. Upoyo AS, Setyopranoto I, Pangastuti HS. The modifiable risk factors of uncontrolled hypertension in stroke:Asystematic review and meta-analysis. Stroke Res Treat. 2021;2021:6683256. https://doi.org/10.1155/2021/6683256

PMid:33680423

7. Fuchs FD, Whelton PK. High blood pressure and cardiovascular disease. Hypertension. 2020;75(2):285-92.

PMid:31865786

8. Upoyo AS, Isworo A, Sari Y, Taufik A, Sumeru A, Anam A Determinant factors stroke prevention behavior among hypertension patient in Indonesia. Open Access Maced J Med Sci. 2021;9(E):336-9. https://doi.org/10.3889/ oamjms. 2021.6040

9. Chimberengwa PT, Naidoo M. Knowledge, attitudes and practices related to hypertension among residents of a disadvantaged rural communityin SouthernZimbabwe. PLoSOne. 2019;14(6):e0215500. https://doi.org/10.1371/journal.pone.0215500 PMid:31237883

10. LvX, Niu H, QuY, Li M, Li L, MaX, et al. Awareness, treatment and control of hypertension among hypertensive patients aged 18 to 59 years old in the northeast of China. Sci Rep. 2018;8(1):17019. https://doi.org/10.1038/s41598-018-34923-5 PMid:30451878

11. Gamage DG, Riddell MA, Joshi R, Thankappan KR, Chow CK Oldenburg B, et al. Effectiveness of a scalable group-based education and monitoring program, delivered by health workers, to improve control of hypertension in rural India: A cluster randomised controlled trial. PLoS Med. 2020;17(1):e1002997. https://doi.org/10.1371/journal.pmed.1002997

PMid:31895945 
12. Han $H R$, Lee $H$, Commodore-Mensah $\mathrm{Y}, \operatorname{Kim} \mathrm{M}$ Development and validation of the hypertension self-care profile: A practical tool to measure hypertension self-care. J Cardiovasc Nurs. 2014;29(3):E11-20. https://doi.org/10.1097/ jcn.0b013e3182a3fd46

PMid:24088621

13. DeVon HA, Block ME, Moyle-Wright P, Ernst DM, Hayden SJ Lazzara DJ, et al. A psychometric toolbox for testing validity and reliability. J Nurs Scholarsh. 2007;39(2):155-64. https://doi. org/10.1111/j.1547-5069.2007.00161.x

PMid:17535316

14. Orem DE. Nursing Concepts of Practice. $6^{\text {th }}$ ed. Mosby: Elsevier; 2001.

15. Tomey AM, Alligood MR. Nursing Theorists and Their Work. $6^{\text {th }}$ ed. Mosby: Elsevier; 2006.
16. Yaghmai F. Content validity and its estimation. J Med Educ. 2003;3(1):25-7.

17. Ministry of Health of the Republic of Indonesia. Regulation of the Minister of Health of the Republic of Indonesia Number 41 of 2014 Concerning Guidelines for Balanced Nutrition; 2016. Available from: https://www.kesmas.kemkes.go.id/perpu/ konten/permenkes/pmk-no.-41-ttg-pedoman-gizi-seimbang. [Last accessed on 2020 Sep 10].

18. Kline RB. Book review: Psychometric theory. J Psychoeduc Assess. 1999;17:275-80.

19. Sowtali SN, Yusoff DM, Harith S, Mohamed M. Translation and validation of the Malay version of the stroke knowledge test. J Arrhythm. 2016;32(2):112-8. https://doi.org/10.1016/j. joa.2015.10.003

PMid:27092192 